UDC 614.31.613.292.614.35.615.31.543.51.543.54.544.1.547.7.547.8

DOI: $10.21668 /$ health.risk/2019.3.06.eng

\title{
SCREENING RESULTS FOR NON-DECLARED SYNTHETIC PHOSPHODIESTERASE-5 INHIBITORS BEING ADDED TO DIETARY SUPPLEMENTS OF PLANT ORIGIN
}

\section{I.B. Perova, K.I. Eller, E.V. Tumol`skaya}

Federal research centre of nutrition and biotechnology, 2/14 Ustinskiy Proezd, Moscow, 109240, Russian Federation

Non-declared addition of synthetic phosphodiesterase-5 inhibitors (PDE-5 inhibitors) to dietary supplements (DS) of plant origin in order to stimulate potency is a serios problem. Such counterfeiting strengthens therapeutic effects produced by a product; similar effects can't occur only due to components of DS of plant origin. Synthetic PDE-5 inhibitors are both substances of official medications and their structural analogues. When synthetic PDE-5 inhibitors are consumed as components in DS in order to increase potency, it can be hazardous for consumers' health due to unpredictable or even lethal side effects.

Our research goal was to reveal concentrations of non-declared synthetic PDE-5 inhibitors in DS consumed by males. Our research objects were 175 DS selected by Rospotrebnadzor in different Russian regions. Synthetic PDE-5 inhibitors were detected in samples by HPLC with diode array spectrophotometric detection and MS-detection as per guidelines developed by us and approved on by Rospotrebnadzor (MG 4.1.3331-16).

Our research revealed that $36 \%$ of DS that were consumed to increase potency contained non-declared synthetic PDE-5 inhibitors with Tadalafil and Sildenafil being the most widely spread ones $42.9 \%$ and $28.6 \%$ of all counterfeit cases). Their combination or analogues of PDE-5 inhibitors were detected significantly less frequently; complicated mixtures containing three or more components were also rather rare. Contents of Tadalafil, Sildenafil, or Vardenafil in DS varied from trace quantities to concentrations that corresponded to recommended daily doses for these medications or even higher than such doses. We identified derivatives of Sildenafil and Tadalafil among PDE-5 inhibitors; their quantities varied from $1.2 \mathrm{mg} /$ capsule to $24.3 \mathrm{mg} / \mathrm{capsule}$.

The developed procedure allowed detecting counterfeited DS with not only Tadalafil, Sildenafil, or Vardenafil being added to them, but also analogues of synthetic PDE-5 inhibitors.

Key words: DS, safety, health risk, Synthetic phosphdiesterase-5 inhibitors, Tadalafil, Vardenafil, Sildenafil, HPLC-DAD-MS.

Vegetable biologically active additives (BAAs) to food that are used to stimulate potency are widely spread all over the world and considered to be safe. But it is such additives that are the most frequently falsified as they contain non-declared drug substances that are added to raise their stated efficiency. These additives are applied to stimulate potency in case there is overall weakening of a body but they are non-efficient in case of erective dysfunction (ED) which occurs due to diseases in the urogenital system. BAAs to food aimed at stimulating potency usually contain certain aphrodisiacs (extracts of barrenwort, ginseng, magnolia-vine, eleutherococcus, yohimbe, damiana, etc.), prostate protectors (extracts of cinquefoil, pumpkin seeds, palmetto, yam, licorice, ground burnuts, etc.), antioxidants (coenzyme $\mathrm{Q}_{10}$, extracts of maidenhair tree, tomatoes, Acai

(C) Perova I.B., Eller K.I., Tumol'skaya E.V., 2019

Irina B. Perova - Candidate of Pharmaceutical Sciences, Researcher at the Laboratory for Metabolomic and Proteome Analysis (e-mail: Erin.Feather@yandex.ru; tel.: +7 (495) 698-53-92; ORCID: https://orcid.org/0000-00015975-1376).

Konstantin I. Eller - Doctor of Chemical Sciences, Head of the Laboratory for Metabolomic and Proteome Analysis (e-mail: eller@ion.ru; tel.: +7 (495) 698-54-07;ORCID: https://orcid.org/0000-0003-1046-4442).

Elena V. Tumolskaya - Junior researcher at the Laboratory for Metabolomic and Proteome Analysis (e-mail: tum.elena@mail.ru; tel.: +7 (495) 698-53-92; ORCID: https://orcid.org/0000-0002-3913-0799). 
palm, etc.), vitamins (especially A, E, and $\mathrm{PP}$ ), and microelements (selenium, zinc and some others). At the same time accomplished research revealed that potencystimulating BAAs to food contained not only declared vegetable components but also synthetic phosphodiesterase-5 inhibitors (PDA-5 inhibitors).

These drugs are selective inhibitors of $\mathrm{c}-$ GMP-specific phosphodiesterase-5 (PDE-5) that metabolizes c-GMP into 5'-GMP in smooth muscles cells of blood vessels that supply blood to cavernous bodies of the penis (and artery walls in the lungs). PDE-5 blocking is accompanied with c-GMP accumulation and stronger and longer erection when sexual arousal occurs. So, PDE-5 inhibitors are applied to treat ED and pulmonary hypertension. At present there are four drugs belonging to PDE-5 inhibitors group that are registered in the RF: Sildenafil (Viagra $^{\circledR}$, Pfizer), Tadalafil (Sialis ${ }^{\circledR}$, ElliLilly), Vardenafil (Levitra ${ }^{\circledR}$, Bayer), and Udenafil
(Zidena $^{\circledR}$, Dong-A Pharmaceutical Co. Ltd) ${ }^{1}$. The latter is also registered in South Korea and Malaysia [1]. In the USA and EU there is another allowed drug in this group in addition to Tadalafil, Vardenafil, and Udenafil, namely Avanafil (Stendra ${ }^{\circledR}$, Vivus; Spedra ${ }^{\circledR}$, Mitsubishi Tanabe Pharma) [2]. There is another PDE-5 inhibitor allowed in South Korea; it is called Mirodenafil (Mvix ${ }^{\circledR}$, SK ChemicalsLifeScience) [1]. Lodenafil carbonate is applied in Brazil to treat ED $\left(\right.$ Helleva $^{\circledR}$, Cristália Produtos Quími-cose Farmacêuticos) [3]. Chemical structures of all the drugs from PDE-5 inhibitors group are shown in Figure 1.

In some cases falsified BAAs to food contained structural analogs of PDE-5 inhibitors that were not registered as pharmaceutical substances but produced the same pharmacological effects. Since 2003 a lot of research work has been accomplished with its focus on discovering and identifying various analogs of Sildenafil, Tadalafil, and

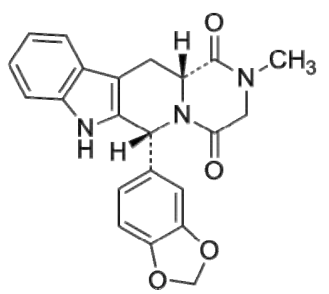

Tadalafil

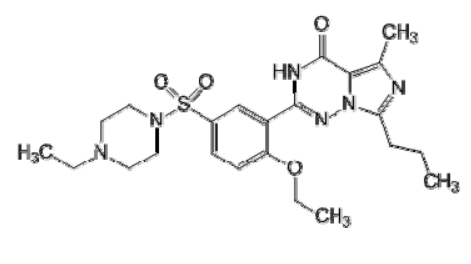

Vardenafil

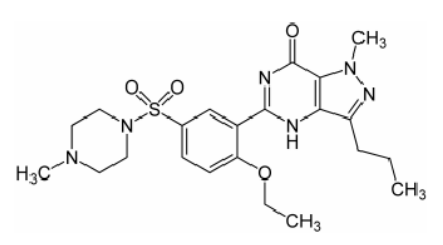

Sildenafil

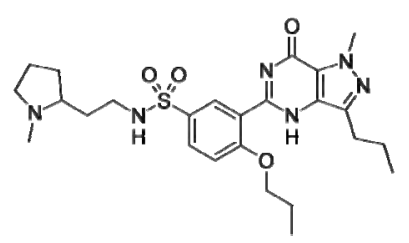

Udenafil

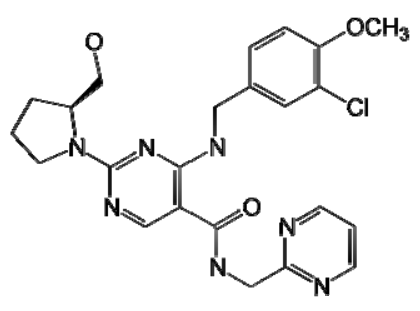

Avanafil

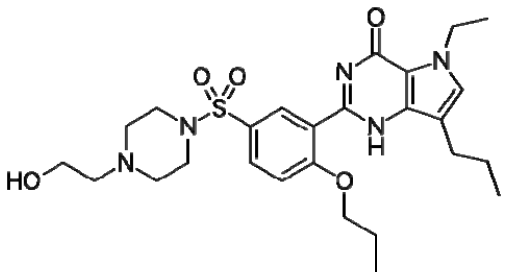

Mirodenafil

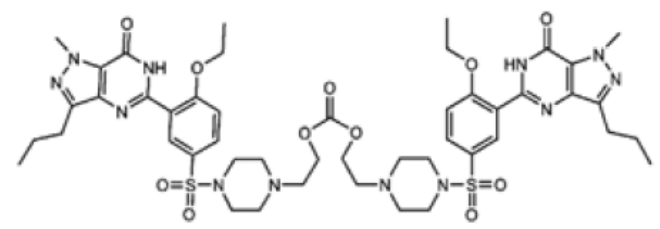

Lodenafil carbonate

Figure 1. Chemical structures of PDE-5 inhibitors

${ }^{1}$ The State Register of Medications. Available at: https://grls.rosminzdrav.ru/Default.aspx (date of visit March 23, 2019). 
Vardenafil via high-performance liquid chromatography (HPLC) with diode-array detector (DAD) and mass-spectrometric detectors with high and low resolution as well as infra-red spectroscopy and nuclearmagnetic resonance spectroscopy [4-32]. So, by 2018 approximately 80 synthetic PDE-5 inhibitors have been discovered in potencystimulating BAAs to food, Sildenafil analogs prevailing among them [33].

Synthetic substances that are illegally included into BAAs to food create substantial hazards for consumers' health. While there is available information on toxicity, counter-indications, side effects, and maximum single or daily dose for PDE-5 inhibitors allowed to be used in medical practices, there is practically no such information for most their analogs. Hypersensitivity to PDE5 inhibitors and simultaneous intake of nitrates or other nitrogen oxide donators are counter-indications to intake of these drugs. Safety precautions and limitations imposed on taking these drugs mostly concern men with cardiovascular diseases, diabetes, those who are older than 71 , men suffering from hereditary degenerative diseases of the eye retina, and those prone to priapism. Besides, quality, efficiency, and safety of PDE-5 inhibitors that are allowed to be used in medical practices are controlled by public healthcare authorities while there are no such procedures for illegally manufactured substances. Therefore, taking non-declared substances contained in BAAs to food can result in grave side effects, especially when it comes to analogs that have not been registered as pharmaceutical substances as their safety has never been examined and their interaction with other drugs can be unpredictable or even lethal.
Our research goal was to detect contents of non-declared synthetic PDE-5 inhibitors in potency-stimulating BAAs to food.

In order to protect population health and provide safety and quality of BAAs to food consumed by men, in 2015 Rospotrebnadzor started examining possible BAAs falsifications with synthetic PDE-5 inhibitors. Analytical tasks that are to be solved by test laboratories in order to perform control over potency-stimulating BAAs to food are rather complicated due to a great number of synthetic PDE-5 inhibitors (there are approximately 100 known substances and 80 of them have been detected in BAAs to food), standard substances being available, unfair manufacturers being too creative (they add exotic analogues and their mixtures into BAAs or include PDE-5 inhibitors into a cover of a capsule), and a great variety of BAAs matrixes. Given that, it has become necessary to develop a new methodology that would allow detecting synthetic PDE-5 inhibitors in a multi-component matrix of a BAA to food; it was the main task of our research.

Data and methods. We accomplished our research on Agilent 1100 liquid chromatographer with degasser, binary pump, column thermostat, constant-temperature autosampler, diode-array spectrophotometric detector (DAD), and time-of-flight Agilent 6210 LC/MS-TOF mass-spectrometric detector (Agilent Technologies, the USA); we also applied Ultimate 3000 system for liquid chromatography equipped with degasser, two three-channel pumps, column thermostat, constant-temperature autosampler, DAD, and TSQ Endura triple quadruple mass-spectrometric detector (Thermo Fisher Scientific, the USA).

\footnotetext{
${ }^{2}$ MUK 4.1.3331-16. The procedure for measuring a mass fraction of synthetic PDE-5 inhibitors (Tadalafil, Vardenafil, and Sildenafil) in biologically active additives to food via high-performance liquid chromatography with ultraviolet and mass-spectrometric detecting: Methodical guidelines. Available at: http://www.rospotrebnadzor.ru/documents/details.php?ELEMENT_ID=6314 (date of visit March 23, 2019).
} 
Our research objects were BAAs to food consumed by men including those applied to stimulate potency; BAAs were selected by Rospotrebnadzor experts in different RF regions. Overall, we analyzed 175 samples.

In order to solve tasks formulated by Rospotrebnadzor, we developed and metrologically tested a procedure for measuring a mass fraction of synthetic PDE-5 inhibitors (Tadalafil, Vardenafil, and Sildenafil) in biologically active additives via high-performance liquid chromatography with ultraviolet and mass-spectrometric detecting; in 2016 the procedure was granted a status of being the Methodical guidelines MUK 4.1.3331-16².

Results and discussion. Our research revealed that $36 \%$ of BAAs to food consumed by men contained non-declared synthetic PDE-5 inhibitors. We should note that we applied the fixed procedure for measuring a mass fraction of synthetic PDE-5 inhibitors and it allowed us to determine not only Tadalafil, Vardenafil, and Sildenafil in BAAs to food but also some analogs of drugs from PDE-5 inhibitors group with various chemical structures.

Detected BAAs falsifications with synthetic PDE-5 inhibitors are given in Figure 2.

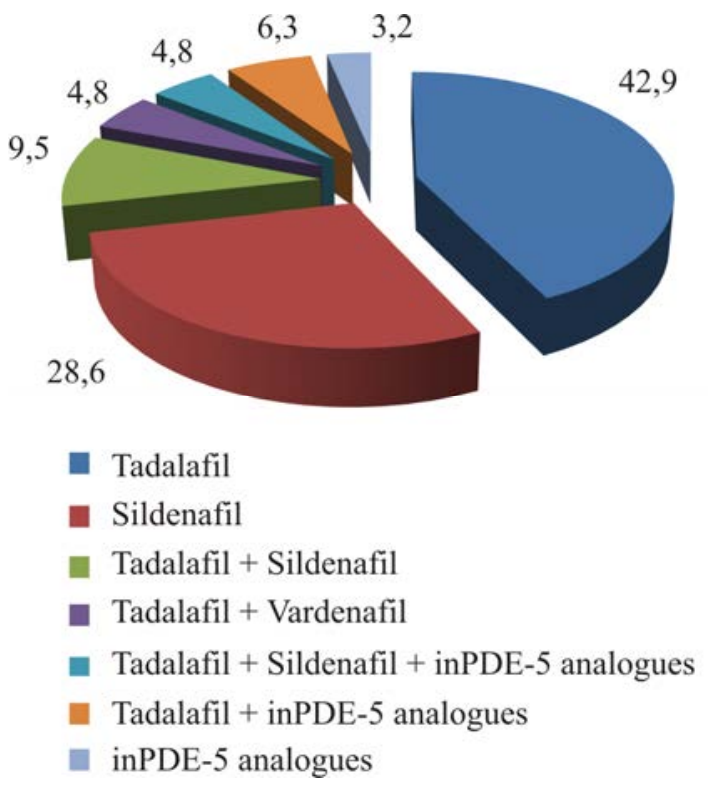

Figure 2. Distribution of BAAs falsifications with synthetic PDE-5 inhibitors (\%)
As we can see from Figure 2, Tadalafil and Sildenafil prevailed among non-declared PDE-5 inhibitors in BAAs to food $(42.9 \%$ and $28.6 \%$ of all falsifications respectively). Typical chromatograms of extractions from BAAs containing Tadalafil are given in Figure 3.

Tadalafil and Sildenafil combinations were less frequent $(9.5 \%)$; they were followed by combinations of Tadalafil with other synthetic PDE-5 inhibitors (6.3\%); combinations of Tadalafil and Vardenafil (4.8\%); and combinations of Tadalafil, Sildenafil, and other synthetic PDE-5 inhibitors $(4.8 \%)$. The rarest falsifications were those with structural analogs of drugs from PDE-5 inhibitors group as they accounted for only 3.2\%.

Quantity of non-declared synthetic PDE-5 inhibitors in BAAs to food varied greatly starting from trace concentrations $(0.004-1.0 \mathrm{mg} /$ capsule (pill, etc.)) that couldn't produce any pharmacological effects to concentrations comparable with recommended daily doses for respective drugs or being even higher than them (Table 1).

We identified derivatives of Sildenafil (Homosildenafil, Tiosildenafil, Hydroxyhomotiosildenafil), Tadalafil (Aminotadalafil), and Acetyldenafil (Metoxyacetyldenafil) among structural analogs of drugs from PDE-5 inhibitors group detected in BAAs to food.

Table 2 contains data on chemical structures of these substances, wave lengths of maximum absorptions in UV-part of a spectrum, molecular masses and protonated ion masses.

Hiomosildenafil was detected in BAAs to food in a quantity equal to $1.2-1.8 \mathrm{mg} / \mathrm{capsule}$ (pill) and it was combined with Tadalafil or Tadalafil and Sildenafil. A typical chromatogram for such a combination of PDE-5 inhibitors is shown in Figure 4.

Another falsification was a combination of Hydroxytiohomosildenafil in a concentration equal to $15.3 \mathrm{mg} /$ capsule and a derivative of Acetyldenafil with Tadalafil. The rarest falsification (only $3.2 \%$ of all falsification cases) was only one PDE-5 inhibitor analog added to a BAA to food; such analogs were either Tiosildenafil or Aminotadalafil and 
they were detected in concentrations equal to $24.3 \mathrm{mg} / \mathrm{capsule}$ and $12.2 \mathrm{mg} / \mathrm{capsule}$ respectively. As analogs of PDE-5 inhibitors have not been properly examined we don't have any available data on their single and daily pharmacological doses and it complicates assessment of risks caused by their contents in consumed BAAs to food.
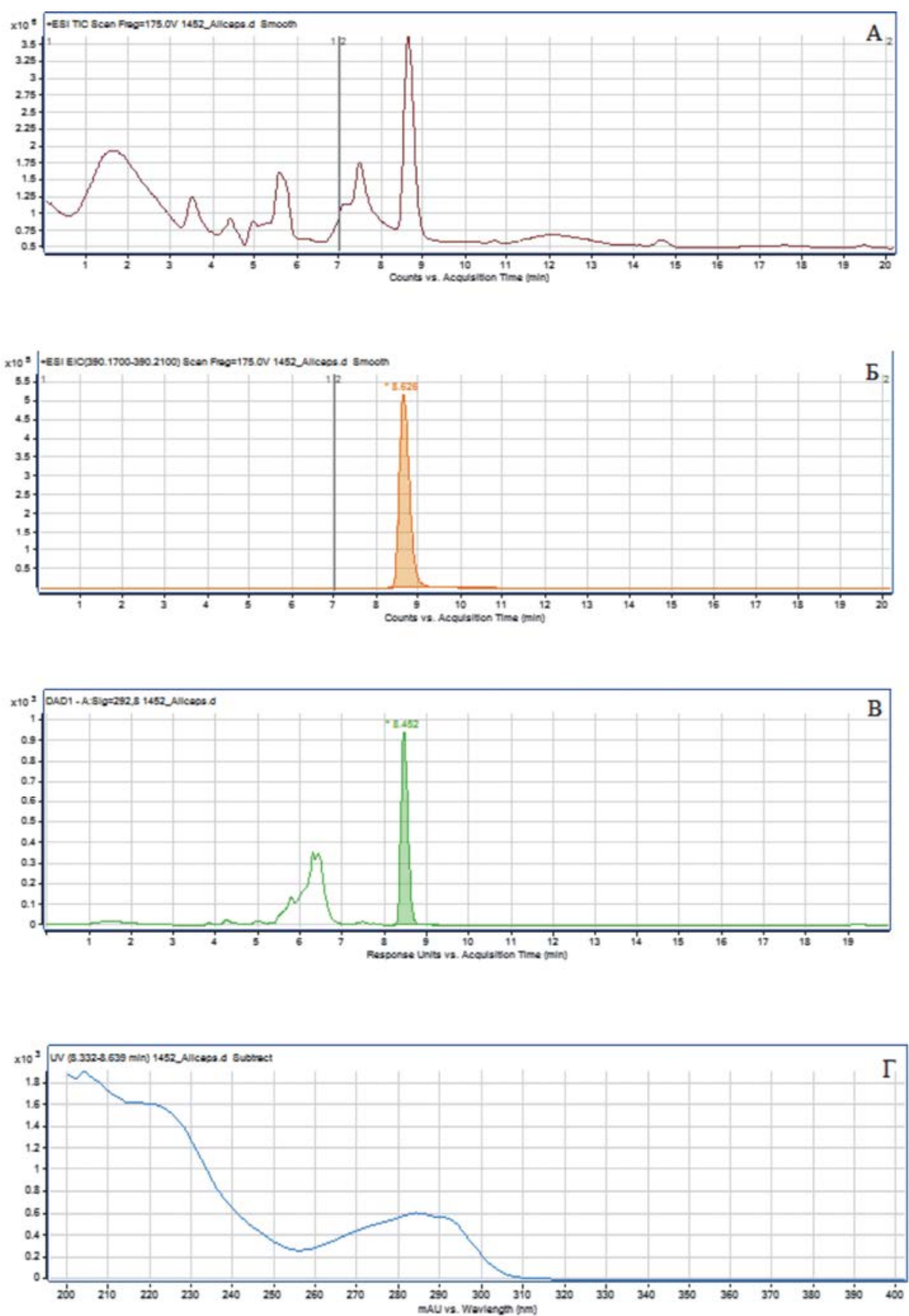

Figure 3. Chromatograms showing extractions from BAAs to food that contained Tadalafil. $A$ is total ion current (TIC). $\mathrm{B}$ is extracted ion chromatogram (EIC) of Tadalafil with $\mathrm{m} / \mathrm{z} 390$. $\mathrm{B}$ is a chromatogram showing extraction form a BAA to food at $\lambda=292 \mathrm{~nm}$. $\Gamma$ is an UV-spectrum of Tadalafil in a BAA to food 
Table 1

Recommended daily doses of Tadalafil, Sildenafil, and Vardenafil, and their quantities detected in examined BAAs to food

\begin{tabular}{|c|c|c|}
\hline $\begin{array}{c}\text { Substances from PDE-5 } \\
\text { inhibitors group }\end{array}$ & Recommended daily dose, mg & $\begin{array}{c}\text { Detected in a BAA to food, } \\
\text { mg/capsule (pill) }\end{array}$ \\
\hline Tadalafil & $5-20$ & $0.004-26.7$ \\
\hline Sildenafil & $25-100$ & $0.001-115.8$ \\
\hline Vardenafil & $5-20$ & $0.1-14.0$ \\
\hline
\end{tabular}

Table 2

Structure formulas, UV maximum absorptions, molecular masses, and protonated ion masses $[\mathrm{M}+\mathrm{H}]^{+}$of PDE-5 inhibitors analogs detected in BAAs to food

\begin{tabular}{|c|c|c|c|c|}
\hline $\begin{array}{c}\text { Analog of PDE-5 } \\
\text { inhibitor }\end{array}$ & Structure formula & $\lambda_{\max }, \mathrm{nm}$ & $\mathrm{M}, \mathrm{gr} / \mathrm{mol}$ & {$[\mathrm{M}+\mathrm{H}]^{+}$} \\
\hline Homosildenafil & & 294 & 488.6 & 489 \\
\hline Tiosildenafil & & 295,355 & 490.6 & 491 \\
\hline $\begin{array}{l}\text { Hydroxyhomotio- } \\
\text { sildenafil }\end{array}$ & & 295,355 & 520.6 & 521 \\
\hline Aminotadalafil & & $\begin{array}{l}270 \text { arm, } \\
284,292\end{array}$ & 390.39 & 391 \\
\hline Metoxyacetyldenafil & & $\begin{array}{l}230 \\
280\end{array}$ & 496.6 & 497 \\
\hline
\end{tabular}



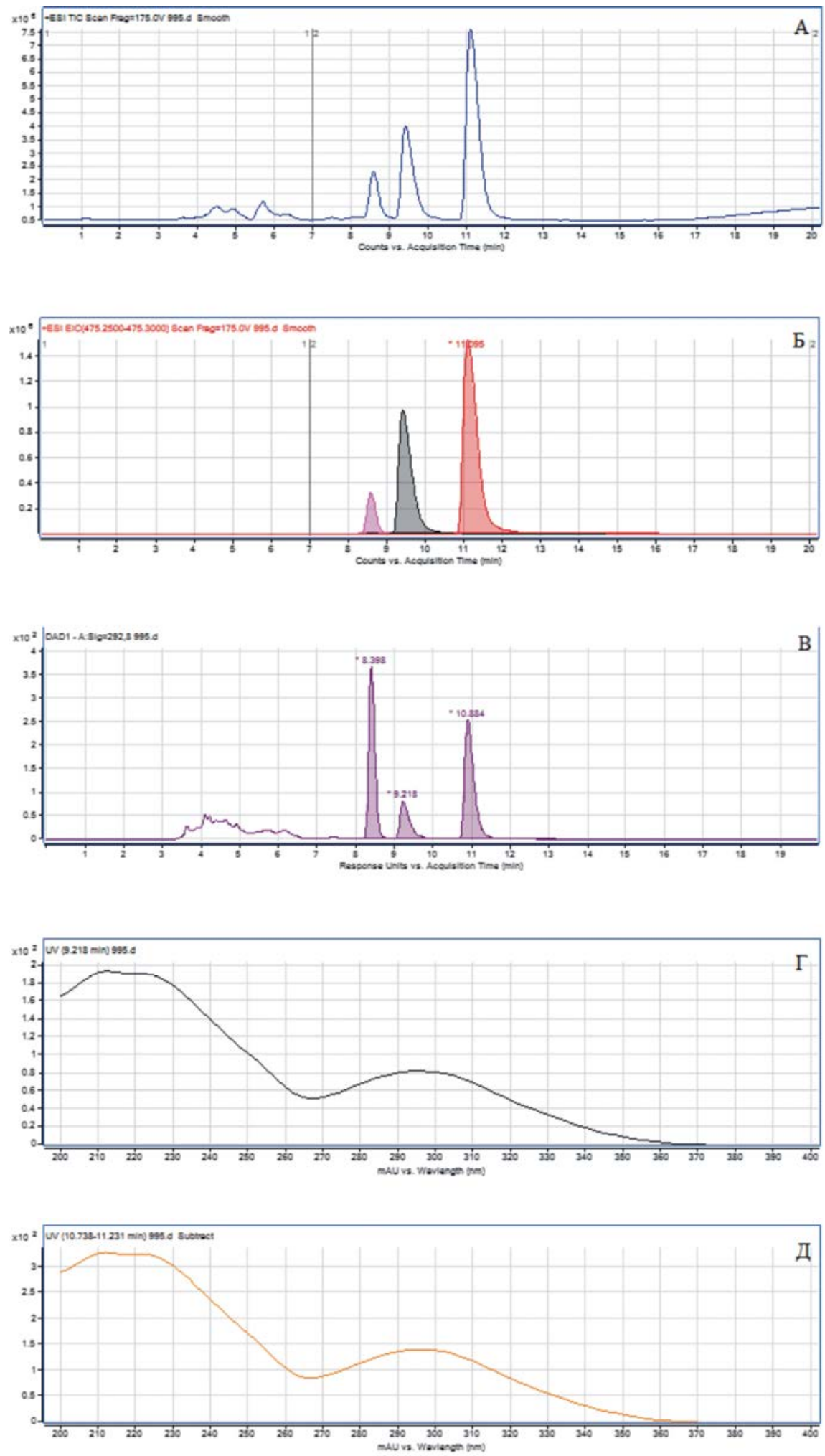

Figure 4. Chromatograms showing an extraction from a BAA to food that contained Tadalafil, Sildenafil, and Homosildenafil. A is total ion current (TIC). Б is extracted ions chromatogram (EIC) showing Tadalafil ions with $\mathrm{m} / \mathrm{z} 390$ (8.6 minutes), Homosildenafil ions with $\mathrm{m} / \mathrm{z} 489$ (9.4 minutes), and Sildenafil ions with $\mathrm{m} / \mathrm{z} 475$ (11.1 minutes). B is a chromatogram of extraction from a BAA to food at $\lambda=292 \mathrm{~nm}$.

Retention time amounts to 8.4 minutes for Tadalafil; 9.2 minutes, for Homosildenafil; and 10.9 minutes, for Sildenafil. $\Gamma$ is an UV-spectrum of Homosildenafil in a BAA to food. Д is an UV-spectrum of Sildenafil in a BAA to food 
Conclusions. Our research revealed that the fixed procedure allowed detecting concentrations of not only Tadalafil, Vardenafil, and Sildenafil, but also some structural analogs of drugs from PDE-5 inhibitors group. Obtained data are applied when a BAA to food is certified by state authorities. In particular, a sanitary-epidemiologic inspection of a potencystimulating BAA to food obligatorily includes checking whether a BAA to food contains non-declared synthetic PDE-5 inhibitors. Research results can be considered a database necessary for assessing potential health risks.

Funding. The research was not granted any financial support.

Conflict of interests. The authors declare there is no any conflict of interests.

\section{References}

1. Moon D.G. Evolution of PDE5 inhibitors in Korea. Transl. Androl. Urol., 2015, vol. 4, no. 1, pp. AB041. DOI: 10.3978/j.issn.2223-4683.2015.s041

2. Huang S.A., Lie J.D. Phosphodiesterase-5 (PDE-5) inhibitors in the management of erectile dysfunction. Pharmacy and Therapeutics, 2013, vol. 38, no. 7, pp. 414-419.

3. Peak T.C., Yafi F.A., Sangkum P., Hellstrom W.J.G. Emerging drugs for the treatment of erectile dysfunction. Expert Opinion on Emerging Drugs, 2015, vol. 20, pp. 263-275.

4. Shin M.H., Hong M.K., Kim W.S., Lee Y.J., Jeong Y.C. Identification of a new analogue of sildenafil added illegally to a functional food marketed for penile erectile dysfunction. Food Addit. Contam., 2003, vol. 20, no. 9, pp. 793-796.

5. Blok-Tip L., Zomer B., Bakker F., Hartog K.D., Hamzink M., Ten Hove J., Vredenbregt M., De Kaste D. Structure elucidation of sildenafil analogues in herbal products. Food Addit. Contam., 2004, vol. 21, no. 8, pp. 737-748. DOI: 10.1080/02652030412331272467

6. Zou P., Oh S.S., Hou P., Low M.Y., Koh H.L. Simultaneous determination of synthetic phosphodiesterase- 5 inhibitors found in a dietary supplement and pre-mixed bulk powders for dietary supplements using high-performance liquid chromatography with diode array detection and liquid chromatography-electrospray ionization tandem mass spectrometry. J. Chromatogr. A, 2006, vol. 1104, no. 1-2, pp. 113-122. DOI: 10.1016/j.chroma.2005.11.103

7. Park H.J., Jeong H.K., Chang M.I., Im M.H., Jeong J.Y., Choi D.M., Park K., Hong M.K. [et al.]. Structure determination of new analogues of vardenafil and sildenafil in dietary supplements. Food Addit. Contam., 2007, vol. 24, no. 2, pp. 122-129. DOI: 10.1080/02652030600983625

8. Lam Y.H., Poon W.T., Lai C.K., Chan A.Y., Mak T.W. Identification of a novel vardenafil analogue in herbal product. J. Pharm. Biomed. Anal., 2008, vol. 46, no. 4, pp. 804-807. DOI: 10.1016/j.jpba.2007.12.004

9. Zou P., Hou P., Oh S.S.Y., Ge X., Bloodworth B.C., Low M.Y., Koh H.L. Identification of benzamidenafil, a new class of phosphodiesterase- 5 inhibitor, as an adulterant in a dietary supplement. J. Pharm. Biomed. Anal., 2008, vol. 47, no. 2, pp. 255-259. DOI: 10.1016/j.jpba.2008.01.004

10. Reepmeyer J.C., d'Avignon D.A. Structure elucidation of thioketone analogues of sildenafil detected as adulterants in herbal aphrodisiacs. J. Pharm. Biomed. Anal., 2009, vol. 49, no. 1, pp. 145-150. DOI: $10.1016 /$ j.jpba.2008.10.007

11. Balayassac S., Trefi S., Gilard V., Malet-Martino M., Martino R., Delsuk M.A. 2D and 3D DOSY 1H-NMR, a useful tool for analysis of complex mixtures: application to herbal drugs or dietary supplements for erectile dysfunction. J. Biomed. Anal., 2009, vol. 50, no. 4, pp. 602-612. DOI: 10.1016/j.jpba.2008.10.034

12. Lee H.M., Kim C.S., Yang Y.M., Kwon S.W., Lee B.J. Separation and structural elucidation of a novel analogue of vardenafil included as an adulterant in a dietary supplement by liquid chromatography-electrospray ionization mass spectrometry, infrared spectroscopy and nuclear magnetic resonance spectroscopy. J. Pharm. Biomed. Anal., 2011, vol. 54, no. 3, pp. 491-496. DOI: 10.1016/j.jpba.2010.09.022

13. Venhuis B.J., Zomer G., Hamzink M., Meiring H.D., Aubin Y., De Kaste D. The identification of a nitrosatedprodrug of the PDE-5 inhibitor aildenafil in a dietary supplement: A Viagra with a pop. J. Pharm. Biomed. Anal., 2011, vol. 54, no. 4, pp. 735-741. DOI: 10.1016/j.jpba.2010.11.020 
14. Lee H.M., Lee B.J. A novel approach to simultaneous screening and confirmation of regulated pharmaceutical compounds in dietary supplements by LC/MS/MS with an informationdependent acquisition method. Food Addit. Contam. Part. A. Chem. Anal. Control Expo. Risk assess, 2011, vol. 28, no. 4, pp. 396-407. DOI:10.1080/19440049.2011.551947

15. Sacré P.Y., Deconinck E., Chiap P., Crommen J., Mansion F., Rozet E., Courselle P., De Beer J.O. Development and validation of a ultra-high-performance liquid chromatography-UV method for detection and quantification of erectile dysfunction drugs and some of their analogues found in counterfeit medicines. J. Chromarogr. A, 2011, vol. 1218, no. 37, pp. 6439-6447. DOI: 10.1016/j.chroma.2011.07.029

16. Balayssac S., Gilard V., Zedde C., Martino R., Malet-Martino M. Analysis of herbal dietary supplements for sexual performance enhancement: first characterization of propoxyphenyl-thiohydroxyhomosildenafil and identification of sildenafil, thiosildenafil, phentolamine and tetrahydropalmatine as adulterants. J. Pharm. Biomed. Anal., 2012, vol. 63, pp. 135-150. DOI: 10.1016/j.jpba.2012.01.035

17. Vaysse J., Gilard V., Balayssac S., Zedde C., Martino R., Malet-Martino M. Identification of a novel sildenafil analogue in an adulterated herbal supplement. J. Pharm. Biomed. Anal., 2012, vol. 59, pp. 58-66. DOI:10.1016/j.jpba.2011.10.001

18. Sakamoto M., Moriyasu T., Minowa K., Kishimoto K., Kadoi H., Hamano T., Fukaya H. Structure elucidation of a novel analog of sildenafil detected as an adulterant in a dietary supplement using LC-UV and LC/MS. Journal of AOAC International, 2012, vol.95, no. 4, pp. 1048-1052.

19. Liao Y.-C., Lai K.-C., Lee C., Liu Y.-C., Lin Y.-L., Shin D.Y.-C. Isolation and identification of new sildenafil analodues from dietary supplements. Journal of Food and Drug Analysis, 2013, vol. 21, no. 1, pp. 40-49. DOI:10.6227/jfda.2013210105

20. Campbell N., Clark J.P., Stecher V.J., Thomas J.W., Callanan A.C., Donnelly B.F., Goldstein I., Kaminetsky J.C. Adulteration of purported herbal and natural sexual performance enhancement dietary supplements with synthetic phosphodiesterase type 5 inhibitors. J. Sex. Med., 2013, vol. 10, no.7, pp. 1842-1849. DOI:10.1111/jsm.12172

21. Silva L.M., Filho E.G., Thomasi S.S., Silva B.F., Ferreira A.G., Venancio T. Use of diffusion-ordered NMR spectroscopy and HPLC-UV-SPE-NMR to identify undeclared synthetic drugs in medicines illegally sold as phytotherapies. Magn. Reson. Chem., 2013, vol. 51, no. 9, pp. 541-548. DOI:10.1002/mrc.3984

22. Lee E.S., Lee J.H., Kim J.W., Hwang I.S., Cho S., Han S.Y., Kim J. Simultaneous determination of 38 phosphodiesterase-5 inhibitors in illicit erectile dysfunction products by liquid chromatography-electrospray ionization-tandem mass spectrometry. J. Pharm. Biomed. Anal., 2013, vol. 83, pp. 171-178. DOI: 10.1016/j.jpba.2013.05.009

23. Reeuwijk N.M., Venhuis B.J., De Kaste D., Hoogenboom L.A.P., Rietjens I.M.C.M., Martena M.J. Sildenafil and analogous phosphodiesterase type 5 (PDE 5) inhibitors in herbal food supplements sampled on the Dutch market. Food Additives and Contaminants: Part A, 2013, vol. 30, no. 12, pp. 2027-2034. DOI:10.1080/19440049.2013.848294

24. Mustazza C., Borioni A., Rodomonte A.L., Bartolomei M., Antoniella E., Di Martino P., Valvo L., Sestili I. [et al.]. Characterization of sildenafil analogs by MS/MS and NMR: a guidance for detection and structure elucidation of phosphodiesterase-5 inhibitors. Journal of Pharmaceutical and Biomedical Analysis, 2014, vol. 96, pp. 170-186. DOI: 10.1016/j.jpba.2014.03.038

25. Patel D.N., Li L., Ge X.W., Low M.-Y., Koh H.-L. Screening of synthetic PDE-5 inhibitors and their analogues as adulterants: analytical techniques and challenges. J. Pharm. Biomed. Anal., 2014, vol. 87, pp. 176-190. DOI:10.1016/j.jpba.2013.04.037

26. Shi F., Guo C., Gong L., Li J., Dong P., Zhang J. Application of a high resolution benchtopquadrupole-Orbitrap mass spectrometry for the rapid screening, confirmation and quantification of illegal adulterated phosphodiesterase- 5 inhibitors in herbal medicines and dietary supplements. Journal of Chromatography A, 2014, vol. 1344, pp. 91-98. DOI: 10.1016/j.chroma.2013.12.030

27. Ulloa J., Sambrotta L., Redko F., Mazza O.N., Garrido G., Becher E.F., Muschietti L. Detection of a tadalafil analogue as an adulterant in a dietary supplement for erectile dysfunction. The Journal of Sexual Medicine, 2015, vol. 12, no. 1, pp. 152-157. DOI:10.1111/jsm.12759 
28. Rocha T., Amaral J.S., Oliveira P.B.P.P. Adulteration of dietary supplements by the illegal addition of synthetic drugs: A review. Compr. Rev. Food Sci. F, 2016, vol. 15, pp. 43-62.

29. Redko F., Flor S., Lucangioli S., Ulloa J., Ricco R., Fernandez C., Sambrotta L., Muschietti L. Identification and quantification of an adulterant in a dietary supplement marketed for sexual enhancement. Journal of Advanced Pharmaceutical Science and Technology, 2018, vol. 1, no. 4, pp. 25-33. DOI: 10.14302/issn.2328-0182.japst-18-2344

30. Tucker J., Fisher T., Upjohn L., Mazzera D., Kumar M. Unapproved pharmaceutical ingredients included in dietary supplements associated with US Food and Drug Administration warnings. JAMA Network Open, 2018, vol. 1, no. 6, pp. e183337. DOI: 10.1001/jamanetworkopen.2018.3337

31. Wang X.-B., Zheng J., Li J.-J., Yu H.-Y., Li Q.-Y., Xu L.-H., Liu M.-J., Xian R.-Q. [et al.]. Simultaneous analysis of 23 illegal adulterated aphrodisiac chemical ingredients in health foods and Chinese traditional patent medicines by ultrahigh performance liquid chromatography coupled with quadrupole time-of-flight mass spectrometry. Journal of Food and Drug Analysis, 2018, vol. 26, no. 3, pp. 1138-1153. DOI: 10.1016/j.jfda.2018.02.003

32. Vanhee C., Tuenter E., Kamugisha A., Canfyn M., Moens G., Courselle P., Pieters L., Deconinck E., V.Exarchou. Identification and quantification methodology for the analysis of suspected illegal dietary supplements: reference standard or no reference standard, that's the question. J. Forensic. Toxicol. Pharmacol., 2018, vol. 7, no. 1, pp. 7. DOI:10.4172/2325-9841.1000156

33. Kee C.L., Ge X., Gilard V., Malet-Martino M., Low M.Y. A review of synthetic phosphodiesterase type 5 inhibitors (PDE-5i) found as adulterants in dietary supplements. J. Pharm. Biomed. Anal., 2018, vol. 147, pp. 250-277. DOI:10.1016/j.jpba.2017.07.031

Perova I.B., Eller K.I., Tumol skaya E.V. Screening results for non-declared synthetic phosphodiesterase-5 inhibitors being added to dietary supplements of plant origin. Health Risk Analysis, 2019, no. 3, pp. 50-59. DOI: 10.21668/health.risk/2019.3.06.eng

Received: 29.08 .2019

Accepted: 02.09.2019

Published: 30.09 .2019 